\title{
Seqüenciamento e Variabilidade do Fragmento Genômico de Xylella fastidiosa Amplificado pelos Iniciadores RST31/33*
}

\author{
Adriane Wendland ${ }^{1 * *}$, Daniela Truffi ${ }^{1}$, Rui P. Leite Júnior² \& Luis E. A. Camargo ${ }^{1}$ \\ 'Departamento de Entomologia, Fitopatologia e Zoologia Agrícola, Escola Superior de Agricultura \\ "Luiz de Queiroz", Universidade de São Paulo, Cx. Postal 9, CEP 13418-900, Piracicaba, SP, \\ Fax: (19) 434-4839, e-mail: leacamar@ carpa.ciagri.usp.br; ${ }^{2}$ Área de Proteção de Plantas, \\ Instituto Agronômico do Paraná, Cx. Postal 481, CEP 86001-970, Londrina, PR
}

(Aceito para publicação em 13/11/2001)

Autor para correspondência: Luis E. A. Camargo

WENDLAND, A., TRUFFI, D., LEITE JR., R.P. \& CAMARGO, L.E.A. Seqüenciamento e variabilidade do fragmento genômico de Xylella fastidiosa amplificado pelos iniciadores RST31/33. Fitopatologia Brasileira 28:298-301. 2003.

\section{RESUMO}

Xylella fastidiosa é agente causal de diversas doenças de importância econômica como a clorose variegada dos citros (Citrus spp.) (CVC), mal de Pierce da videira (Vitis vinifera), escaldadura da ameixeira (Prunus salicina) e requeima do cafeeiro (Coffea arabica). A seqüência nucleotídica do fragmento genômico, específico de $X$. fastidiosa, amplificado pelo par de iniciadores RST31/33 foi determinada para 38 isolados de citros e para isolados de videira, cafeeiro e ameixeira objetivando avaliar o nível de polimorfismo entre isolados e a identidade genômica do fragmento.
Não foi observado polimorfismo de sequiência nucleotídica entre isolados de citros, mas foi detectado polimorfismo entre isolados de citros e de videira, cafeeiro e ameixeira. A presença do sítio de clivagem RsaI, que distingue isolados de citros e videira de isolados de ameixeira e outras espécies arbóreas, foi identificada em um isolado de ameixeira proveniente dos EUA mas não em outro proveniente do Brasil.

Palavras-chave adicionais: CVC, polimorfismo de seqüência, seqüenciamento, genes $r p o \mathrm{D}$.

\section{ABSTRACT}

Sequencing and variability of the Xylella fastidosa - specific genomic fragment amplified by the primer pair RST 31/33

Xylella fastidiosa causes several plant diseases of economic importance such as citrus (Citrus spp.) variegated chlorosis (CVC), Pierce's disease of grapevine (Vitis vinifera) and leaf scorch of plum (Prunus salicina) and coffee (Coffea arabica). The nucleotide sequence of the genomic fragment, specific to Xylella fastidosa, amplified by the pair of primers RST 31/33, was determined for 38 isolates from citrus and for isolates from grapevine, coffee and plum in order to assess the level of sequence polymorphism of this fragment among isolates, as well as its genomic identity. Sequence polymorphism was not observed among isolates from citrus, but was detected among isolates from citrus and from grapevine, coffee and plum. The presence of a $R s a \mathrm{I}$ restriction site, which distinguishes isolates from citrus and grapevine from plum and other arboreal species, was identified in a North American isolate from plum but not in a Brazilian one.
A clorose variegada dos citros (Citrus spp.) (CVC) é uma doença de grande importância econômica para a citricultura brasileira devido à redução na produção e qualidade dos frutos (Laranjeira \& Palazzo, 1999). A CVC é causada pela Xylella fastidiosa, bactéria limitada ao xilema, fastidiosa, Gramnegativa, não-móvel, aflagelada, baciliforme, com parede celular enrugada e estritamente aeróbia (Wells et al, 1987). Detectada pela primeira vez em 1987 no Norte do Estado de São Paulo e no Triângulo Mineiro (Rossetti \& De Negri, 1990), a doença foi observada em todas as regiões citrícolas do Brasil.

\footnotetext{
* Parte da Dissertação de Mestrado do primeiro autor. ESALQ/USP ** Bolsista da FAPESP
}

Este patógeno também é responsável por doenças em diversas culturas, como Mal de Pierce em videira (Vitis vinifera L.), "phony peach" em pessegueiro [Prunus persicae (L.) Batsch], escaldadura das folhas em ameixeira (Prunus salicina Lindl) (Wells et al, 1987) e cafeeiro (Coffea arabica L.) (Paradela et al., 1995; Beretta et al., 1996) e outros hospedeiros que englobam espécies de pelo menos 28 famílias de plantas mono e dicotiledôneas (Freitag, 1951; Wells et al., 1987; Hopkins, 1989).

Sequiências de DNA específicas têm sido utilizadas para detecção de $X$. fastidiosa por reação de polimerase em cadeia (PCR) em material vegetal (Minsavage et al., 1994, Pooler \& Hartung, 1995, Beretta et al., 1997). O par de iniciadores RST 
Seqüenciamento e variabilidade do fragmento genômico de Xylella fastidiosa amplificado...

$31 / 33$, por exemplo, produz um fragmento de 733 pb específico para $X$. fastidiosa e tem sido utilizado rotineiramente em exames diagnósticos dessa bactéria (Minsavage et al., 1994). No entanto, a seqüência completa deste fragmento é, até o momento, desconhecida. Segundo os autores, a existência de um sítio de restrição $R s a \mathrm{I}$ neste fragmento possibilita distinguir isolados de citros e videira de isolados de ameixeira e outras espécies arbóreas. Assim, este trabalho objetivou determinar a sequiência deste fragmento e avaliar o nível de polimorfismo de sequiência encontrado entre isolados de citros, videira, ameixeira e cafeeiro.

\section{Coleção de isolados de Xylella fastidiosa}

Folhas de laranjeira (Citrus sinensis L.) 'Pêra' com sintomas de CVC foram coletadas em pomares localizados nas regiões citrícolas do Noroeste (Neves Paulista), Centro (Gavião Peixoto) e Sul (Santa Rita do Passa Quatro) do Estado de São Paulo. O isolamento de $X$. fastidiosa foi realizado de acordo com a metodologia descrita por Hill \& Purcell (1995). Placas contendo meio PWG (Hill \& Purcell, 1995) foram mantidas a $28 \pm 1^{\circ} \mathrm{C}$ até o surgimento das colônias bacterianas. Após o crescimento, foi realizada a purificação dos isolados através da retirada de uma colônia individual para cada isolado com auxílio de alça de platina e distribuição em nova placa contendo meio PWG. Os isolados foram conservados em criotubos contendo meio PW e $30 \%$ glicerol e armazenados $\mathrm{a}-70^{\circ} \mathrm{C}$. Isolados de cafeeiro, videira e ameixeira (Tabela 1) pertencentes à Coleção Bacteriológica da Área de Proteção de Plantas do Instituto Agronômico do Paraná estavam armazenados a $-70^{\circ} \mathrm{C}$ e foram recuperados em placas contendo meio PWG.

\section{Obtenção de DNA genômico de Xylella fastidiosa}

A extração do DNA genômico dos isolados de citros e de outros hospedeiros foi realizada conforme descrito por Ausubel et al. (1992) e a sua concentração foi determinada com fluorômetro DyNA 200 (Hoefer Scientific Instruments, San Francisco, CA, EUA).

\section{Confirmação da identidade dos isolados}

A amplificação do DNA por PCR para confirmação da identidade dos isolados de $X$. fastidiosa (Minsavage, 1994) foi realizada em reações de $25 \mu$ l contendo tampão de amplificação (1X), $100 \mu \mathrm{M}$ de cada dNTP, $50 \mu \mathrm{M}$ dos iniciadores RST31 (5'GCG TTA ATT TTC GAA GTG ATT CGA TTG C-3') e RST33 (5'-CAC CAT TCG TAT CCC GGT G- 3'), 1,25 U Taq DNA polimerase e $3 \mu \mathrm{l}$ de DNA (aproximadamente 30-50 ng). A amplificação por PCR foi realizada em termociclador PTC 100 (MJ Research, Alameda, CA, EUA), inicializada com desnaturação a $95{ }^{\circ} \mathrm{C}$ por 1 min seguida de 40 ciclos de desnaturação a $95^{\circ} \mathrm{C}$ por $30 \mathrm{~s}$, anelamento a $55^{\circ} \mathrm{C}$ por $30 \mathrm{~s}$ e extensão a $72{ }^{\circ} \mathrm{C}$ por $45 \mathrm{~s}$. A extensão final foi realizada a $72{ }^{\circ} \mathrm{C}$ por $5 \mathrm{~min}$. Os produtos amplificados foram resolvidos por eletroforese em gel de agarose (1\%) contendo brometo de etídio $(0,5 \mu \mathrm{g} / \mathrm{ml}$ de gel $)$ à $5 \mathrm{~V} / \mathrm{cm}$. O peso molecular foi comparado ao padrão $1 \mathrm{~Kb}$ (Pharmacia. San Francisco, CA, EUA) e o gel foi fotografado após a corrida com fotodocumentador
ImageMaster VDS (Pharmacia Biotech, San Francisco, CA, EUA) sob luz UV.

\section{Avaliação da freqüência de polimorfismo de seqüência da região amplificada pelos iniciadores RST31 e RST33}

O sequienciamento dos fragmentos amplificados pelos iniciadores RST31/RST33 foi feito por meio de PCR utilizando o kit Big Dye Terminator (Perkin Elmer, Norwalk, CT, EUA). Os fragmentos foram previamente retirados do gel de agarose de baixo ponto de fusão (Promega, Madison, WI, EUA) e purificados por meio do kit Wizard ${ }^{\circledR}$ PCR Preps DNA Purification System (Promega). Para cada reação foi preparada

TABELA 1 - Identificação e origem dos isolados de Xylella fastidiosa

\begin{tabular}{|c|c|c|c|}
\hline Isolado & Hospedeiro & $\begin{array}{c}\text { Data de } \\
\text { Isolamento }\end{array}$ & Localização \\
\hline $9715(755 / 95)$ & Vitis vinifera & 1990 & Austrália \\
\hline 8935 & V. vinifera & 1989 & EUA \\
\hline 9777 & Prunus salicina & 1992 & EUA \\
\hline 12304 & P. salicina & 1997 & Santa Catarina \\
\hline 11752 & Coffea arabica & 1996 & São Paulo, SP \\
\hline 11782 & C. arabica & 1996 & Londrina, PR \\
\hline 12373 & C. arabica & 1999 & Brasília, DF \\
\hline 02.01 & Citrus spp. & 1999 & Neves Paulista, SP \\
\hline 02.02 & Citrus spp. & 1999 & Neves Paulista, SP \\
\hline 02.06 & Citrus spp. & 1999 & Neves Paulista, SP \\
\hline 02.07 & Citrus spp. & 1999 & Neves Paulista, SP \\
\hline 02.08 & Citrus spp. & 1999 & Neves Paulista, SP \\
\hline 07.01 & Citrus spp. & 1999 & Neves Paulista, SP \\
\hline 07.09 & Citrus spp. & 1999 & Neves Paulista, SP \\
\hline 07.25 & Citrus spp. & 1999 & Neves Paulista, SP \\
\hline 07.26 & Citrus spp. & 1999 & Neves Paulista, SP \\
\hline 22.11 & Citrus spp. & 1999 & Neves Paulista, SP \\
\hline 10.06 & Citrus spp. & 1999 & Neves Paulista, SP \\
\hline 09.26 & Citrus spp. & 1999 & Bebedouro, SP \\
\hline 09.34 & Citrus spp. & 1999 & Bebedouro, SP \\
\hline 09.37 & Citrus spp. & 1999 & Bebed ouro, SP \\
\hline 01.31 & Citrus spp. & 1999 & Gavião Peixoto, SP \\
\hline 05.01 & Citrus spp. & 1999 & Gavião Peixoto, SP \\
\hline 05.56 & Citrus spp. & 1999 & Gavião Peixoto, SP \\
\hline 05.24 & Citrus spp. & 1999 & Gavião Peixoto, SP \\
\hline 05.84 & Citrus spp. & 1999 & Gavião Peixoto, SP \\
\hline 05.95 & Citrus spp. & 1999 & Gavião Peixoto, SP \\
\hline 08.05 & Citrus spp. & 1999 & Gavião Peixoto, SP \\
\hline 08.07 & Citrus spp. & 1999 & Gavião Peixoto, SP \\
\hline 08.23 & Citrus spp. & 1999 & Gavião Peixoto, SP \\
\hline 08.41 & Citrus spp. & 1999 & Gavião Peixoto, SP \\
\hline 08.44 & Citrus spp. & 1999 & Gavião Peixoto, SP \\
\hline 08.45 & Citrus spp. & 1999 & Gavião Peixoto, SP \\
\hline 08.46 & Citrus spp. & 1999 & Gavião Peixoto, SP \\
\hline 15.13 & Citrus spp. & 1999 & Gavião Peixoto, SP \\
\hline 22.24 & Citrus spp. & 1999 & Gavião Peixoto, SP \\
\hline 22.42 & Citrus spp. & 1999 & Gavião Peixoto, SP \\
\hline 01.10 & Citrus spp. & 1999 & Santa R. P. Quatro, SP \\
\hline 01.51 & Citrus spp. & 1999 & Santa R. P. Quatro, SP \\
\hline 02.50 & Citrus spp. & 1999 & Santa R. P. Quatro, SP \\
\hline 03.05 & Citrus spp. & 1999 & Santa R. P. Quatro, SP \\
\hline 09.11 & Citrus spp. & 1999 & Santa R. P. Quatro, SP \\
\hline 10.04 & Citrus spp. & 1999 & Santa R. P. Quatro, SP \\
\hline 12.10 & Citrus spp. & 1999 & Santa R. P. Quatro, SP \\
\hline 13.15 & Citrus spp. & 1999 & Santa R. P. Quatro, SP \\
\hline
\end{tabular}


uma mistura contendo $8 \mu \mathrm{l}$ de TRR mix (terminator ready reaction mix), 3,2 pmol do iniciador RST31 para o sentido anverso ou 3,2 pmol do iniciador RST33 para o sentido reverso, 2,5 $\mu 1$ do produto previamente amplificado contendo aproximadamente 30-50 ng de DNA e 8,5 $\mu \mathrm{l}$ de água. A amplificação para seqüenciamento foi realizada de acordo com o protocolo do fabricante (PE Applied Biosystems, Norwalk, CT, EUA). Foi feita nova purificação do produto amplificado por precipitação com isopropanol em microtubos. Após a desnaturação das amostras a $95^{\circ} \mathrm{C}$ por $3 \mathrm{~min}$ foi realizada eletroforese em aparelho ABI Prism 377 DNA SequencerTM (PE Applied Biosystem, Norwalk, CT,EUA)

As seqüências foram alinhadas e comparadas com auxílio do software Sequencher ${ }^{\mathrm{TM}} 3.0$ (Gene Code Corporation, Michigan, EUA) com a finalidade de identificar polimorfismo nas sequiências nucleotídicas. A sequiência dos isolados de $X$. fastidiosa de citros foi comparada às seqüências de outras espécies bacterianas depositadas em banco de dados para identificação de homologia.

A amplificação por PCR do DNA dos isolados de $X$. fastidiosa realizada com os iniciadores RST31/RST33 foi positiva para todas as amostras testadas (dados não apresentados). A seqüência consenso parcial de 587 pb foi obtida através da sobreposição e alinhamento da seqüência de cada um dos isolados em ambos os sentidos. Entre os 38 isolados de citros incluídos neste estudo, não foi observado polimorfismo de seqüência nucleotídica.

As sequiências dos isolados de videira e ameixeira apresentaram polimorfismo quando comparadas às seqüências dos isolados de citros (Tabela 2): os isolados 8935 e 9715 de videira apresentaram um total de sete e três bases distintas, respectivamente; os isolados de ameixeira 9777 (EUA) e 12304 (Brasil) apresentaram polimorfismo (de 8 a 6) em relação aos isolados de citros, mas também apresentaram quatro bases diferentes entre si. O isolado 11782 de cafeeiro apresentou apenas uma única base que o distinguiu dos isolados de citros. Os demais isolados de cafeeiro incluídos neste estudo apresentaram sequiência idêntica à dos isolados de citros.

Minsavage et al. (1994) observaram que a digestão do fragmento RST31/33 com enzima de restrição $R s a$ I gerou produtos que permitiram diferenciar os isolados em dois grupos distintos de $X$. fastidiosa: um grupo correspondente a isolados do mal de Pierce e CVC, cujo fragmento não foi digerido pela enzima, e um outro grupo que inclui isolados de ameixeira e espécies arbóreas, onde a digestão resultou em dois fragmentos de aproximadamente $600 \mathrm{pb}$ e $100 \mathrm{pb}$. Os resultados obtidos a partir do seqüenciamento do fragmento RST31/33 demonstraram que o isolado 9777 de ameixeira procedente dos EUA apresenta o sítio de clivagem $R s a \mathrm{I}$ (GT $\uparrow \mathrm{AC} / \mathrm{CA} \uparrow \mathrm{TG}$ ) na posição 87 (Tabela 2). Por outro lado, em isolados de citros e videira esse sítio não foi identificado, concordando com os resultados obtidos pelos referidos autores. O isolado 12304 de ameixeira procedente do Brasil, ao contrário, não apresentou o sítio de clivagem $R s a \mathrm{I}$, indicando a existência de variabilidade genética entre isolados deste hospedeiro, a necessidade de se avaliar mais isolados de ameixeira do Brasil para compará-los a outros grupos e que a ausência/presença deste sítio não é um bom indicador para agrupar isolados segundo os hospedeiros em que foram coletados. Costa et al. (2000), observaram, também, diferenças entre isolados de ameixeira provenientes dos EUA e Brasil devido ao seu agrupamento com isolados de outros hospedeiros do seu respectivo país de origem.

Embora os isolados de citros e videira sejam considerados do mesmo grupo por Minsavage et al. (1994), devido ao perfil eletroforético semelhante após digestão de DNA com a enzima de restrição $R s a \mathrm{I}$, estudos recentes de variabilidade genética de $X$. fastidiosa evidenciam a sua separação em grupos distintos. Pooler \& Hartung (1995) por exemplo, descrevem uma região específica com inserção de 28 nucleotídeos encontrada no genoma de isolados de citros diferenciandoos de isolados de videira. Leite Jr. et al. (1998) diferenciaram isolados de citros e videira com base na sua similaride genética obtida por eletroforese de campo pulsado com as endonucleases Not I e Sfi I. Os resultados do presente trabalho estão de acordo com estes dois últimos relatos pois, embora tenha demonstrado a ausência de polimorfismo no sítio de restrição de Rsa I entre isolados de videira e de citros, demonstrou a existência de polimorfismos entre isolados destes hospedeiros em outras regiões da seqüência analisada. Assim, um estudo abrangendo mais isolados de cada hospedeiro pode

TABELA 2 - Sequiências parciais do fragmento genômico amplificado pelo par de iniciadores RST 31/33 obtida de isolados de Xilella fastidiosa de citros (Citrus spp.) (0206), videira (Vitis vinifera) (8935, 9715), ameixeira (Prunus salicina) $(9777,12304)$ e cafeeiro (Coffea arabica) (11782) indicando polimorfismos nucleotídicos em negrito e o sítio de restrição GTAC (sublinhado).

\begin{tabular}{|c|c|c|c|c|c|c|c|c|c|c|c|c|c|c|}
\hline \multirow{2}{*}{ Isolado } & \multicolumn{14}{|c|}{ Base } \\
\hline & 87 & 90 & 141 & 146 & 150 & 152 & 196 & 226 & 295 & 304 & 466 & 513 & 515 & 543 \\
\hline 0206 & TC GCAC & $\mathrm{C}$ & $\mathrm{C}: \mathrm{ATG}$ & $\mathrm{C}$ & At & $\mathrm{T}$ & A & A & G & A & $\mathrm{T}$ & $\mathrm{C}$ & $:$ & : \\
\hline 8935 & TC GCAC & $\mathrm{C}$ & C CATG & G & C & C & $\mathbf{G}$ & A & $\mathbf{T}$ & G & $\mathrm{T}$ & $\mathrm{C}$ & : & : \\
\hline 9715 & TC GCAC & $\mathrm{C}$ & $\mathrm{C}: \mathrm{ATG}$ & $\mathrm{C}$ & A & $\mathrm{T}$ & A & A & G & A & C & A & C & : \\
\hline 9777 & TC $\underline{\text { G TAC }}$ & $\mathbf{T}$ & C : CATG & $\mathrm{C}$ & C & $\mathrm{T}$ & G & $\mathbf{G}$ & $\mathbf{T}$ & C & $\mathrm{T}$ & $\mathrm{C}$ & : & : \\
\hline 12304 & TC GCAC & $\mathrm{C}$ & $\mathrm{C}: \mathrm{ATG}$ & $\mathrm{C}$ & C & C & G & $\mathbf{G}$ & $\mathbf{T}$ & G & $\mathrm{T}$ & $\mathrm{C}$ & : & : \\
\hline 11782 & TC GCAC & $\mathrm{C}$ & C : ATG & $\mathrm{C}$ & A & $\mathrm{T}$ & G & A & $\mathrm{T}$ & A & $\mathrm{T}$ & $\mathrm{C}$ & : & $\mathrm{C}$ \\
\hline
\end{tabular}


resultar na identificação de outros sítios de restrição que distinguam isolados destes dois hospedeiros.

\section{REFERÊNCIAS BIBLIOGRÁFICAS}

AUSUBEL, F.M., BRENT, R., KINGSTON, R.E., MOORE, D.D., SEIDMAN, J.G., SMITH, J.A. \& STRUHL, K. Current Protocols in Molecular Biology, New York: Greene Publishing Associates and Wiley-Interscience, 1992.

BERETTA, M.J.G., BARTHE, G.A., CECCARDI, T.L., LEE, R.F. \& DERRICK, K.S.A survey for strains of Xylella fastidiosa in citrus affected by citrus variegated chlorosis and citrus blight in Brazil. Plant Disease 81:1196-1198. 1997.

BERETTA, M.J.G., HARAKAVA, R., CHAGAS, C.M., DERRICK, K.S., BARTHE, G.A., CECCARDI, T.L., LEE, R.F., PARADELA, O., SUGIMORI, M. \& RIBEIRO, I. First report of Xylella fastidiosa in coffee. Plant Disease 80:821. 1996 (Note).

da COSTA, P.I., FRANCO, C.F., MIRANDA, V.S., TEIXEIRA, D.C. \& HARTUNG, J.S. Strains of Xylella fastidiosa rapidly distinguished by arbitrarily primed-PCR. Current Microbiology 40:279-282. 2000.

FREITAG, J.H. Host range of the Pierce's disease virus of grapes as determined by insect transmission. Phytopathology 41:920934. 1951.

HILL, B.L. \& PURCELL, A.H. Acquisition and retention of Xylella fastidiosa by an efficient vector, Graphocephala atropunctata. Phytopathology 85:209-212. 1995.

HOPKINS, D.L. Xylella fastidiosa: Xylem-limited bacterial pathogen of plants. Annual Review of Phytopathology 27:27113290. 1989.

LARANJEIRA, F.F. \& PALAZZO, D.A. Danos qualitativos à produção de laranja 'Natal' causados pela clorose variegada dos citros. Laranja. 20:77-91. 1999.

LEITE JR., R.P., MEHTA, A., CARVALHO, F.M.S. \& UENO, B. Genetic diversity of brazilian strains of Xylella fastidiosa associated with citrus and coffee. Abstracts, XIV, Conference of IOCV, Campinas, SP. 1998. p.156.

MINSAVAGE, G.V., THOMPSON, C.M., HOPKINS, D.L., LEITE, R.M.V.B.C. \& STALL, R.E. Development of a polymerase chain reaction protocol for detection of Xylella fastidiosa in plant tissue. Phytopathology 84:456-461. 1994.

PARADELA FILHO, O., SUGIMORI, M.H., RIBEIRO, I.J.A., MACHADO, M.A., LARANJEIRA, F.F., GARCIA JR., A. \& BERETA, M.J.G. Primeira constatação em cafeeiro no Brasil, da Xylella fastidiosa causadora da clorose variegada dos citros. Laranja 16:135-136. 1995.

POOLER, M.R. \& HARTUNG, J.S. Specific detection and identification of Xylella fastidiosa strains causing citrus variegated chlorosis. Current Microbiology 31:377-381. 1995.

ROSSETTI, V. \& DE NEGRI, D. Clorose variegada dos citros: revisão. Laranja 11:1-14. 1990.

WELLS, J.M., RAJU, B.C., HUNG, H.Y., WEINSBERG, W.G., MANDELCO-PAUL, L. \& BRENNER, D.J. Xylella fastidiosa gen. nov. sp. nov.: Gram-negative, xylem-limited fastidious plant bacteria related to Xanthomonas spp. International Journal of Systematic Bacteriology 37:136-143. 1987. 